\title{
PARTICULATE MATTER EMISSION FROM DUAL FUEL DIESEL ENGINE FUELLED WITH NATURAL GAS
}

\author{
Zdzisław Stelmasiak ${ }^{1}$ \\ Jerzy Larisch ${ }^{1}$ \\ Jacek Pielecha ${ }^{2}$ \\ Dariusz Pietras ${ }^{1}$ \\ ${ }^{1}$ University of Bielsko-Biala, Bielsko - Biała, Poland \\ ${ }^{2}$ Poznan University of Technology, Poznan, Poland
}

\begin{abstract}
The paper presents the results of examination of particulate matter emission from the Diesel engine FPT 1.3 MJT simultaneously fuelled with diesel oil and natural gas $C N G$. The basic premise for engine adaptation was the addition of a small amount of CNG to reduce exhaust gas opacity and particulate matter emission. At this assumption, diesel oil remained the basic fuel, with contribution amounting to 0,70-0,85 of total energy delivered to the engine. The dual fuel engine was examined using an original controller installed in the Diesel engine FPT 1.3 MJT which controlled the diesel fuel dose. The dose of the injected natural gas was controlled by changing the opening time of gas injectors at constant pressure in the gas collector.

The examined issues included the exhaust gas opacity, and the total number and fractional distribution of the emitted particles. The measurements were performed at twenty selected measuring points corresponding to the New European Driving Cycle (NEDC) test. The performed tests have demonstrated a positive effect of gas addition on exhaust gas opacity and particulate matter emission. Depending on test conditions, the exhaust gas opacity was reduced by $10 \div 92 \%$, and the total number of particles by $30 \div 40 \%$.

The performed tests have revealed that a small addition of gas can reduce the load of the DPF filter, extend its lifetime, and increase engine reliability. Longer time intervals between successive DPF filter regenerations improve ecological properties of the engine.
\end{abstract}

Keywords: dual fuel engine, natural gas, particulate matter, emission, opacity, Diesel engine

\section{INTRODUCTION}

An important problem of modern Diesel engines used both in motorisation and marine applications is particulate matter (PM) emission which, due to high hygroscopicity and low density of the emitted particles, compared with the air, creates serious threat for the environment $[1-3,5,7-10,24]$. That is why in two recent decades severe attempts were made to reduce $\mathrm{PM}$ emissions, along with $\mathrm{NO}_{\mathrm{x}}$ emissions, by introducing successively more and more stringent emission standards [21-23]. It is noteworthy here that the object of reduction was not only the mass of the emitted PM, but also the total number PN of particles, with smaller and smaller particle diameters taken into account $[9,10,13,24]$. To meet the above requirements, special Diesel Particulate Filters (DPF) were to be installed in engine exhaust systems to capture extremely small particulates. In practice, these filters are a source of additional flow resistance and have to be frequently cleaned. In unsteady engine operation conditions, at short runs and low temperatures, the DPF filters are a source of severe operating problems which increase engine unreliability.

A basic component of particulates is soot, created as the result of thermal cracking of higher hydrocarbons composing the diesel oil. These hydrocarbons are oxidised in rich flame zones, mainly at oxygen deficiency $[6,9,13]$. A way to reduce the PM emission can be adding oxygenates to the diesel oil [6], or using alcohols, methane gases, or pure methane $[4,7$, $10,12,13]$. A very attractive supplement here seems to be the compressed natural gas, $\mathrm{CNG}$, due to its low price (over twice 
as low as that of petroleum delivered fuels) and high methane content, of about $94 \div 98 \%$ vol.

The main component of the natural gas is methane, $\mathrm{CH}_{4}$. It is a saturated hydrocarbon which is insoluble in water and thus totally harmless to living organisms. It is characterised by a simple oxidation mechanism and good diffusion in air, thanks to which soot particles are not created during combustion, even at oxygen deficiency [13]. Relevant tests have proved that the use of natural gas in Diesel engines decreases the $\mathrm{PM}$ emission, and this decrease depends on gas percentage in the total dose of energy delivered to the engine $[12,13,15,16]$.

However, due to high self-ignition temperature, natural gas requires ignition initiated from another source, which can be a spark-ignition system, or self-ignition of the diesel oil in the double fuel engine $[1,2,4,12,13]$. Due to high compression ratios used in small Diesel engines, the use of a spark-ignition system would require major changes in the engine structure, which seem unjustified in the present transient period, with insufficient number of CNG fuelling stations. However, a Diesel engine can be equipped with a CNG injection system installed close to the inlet valves and thus adapted, at low costs, to dual fuelling $[1,4,7,14,17,20]$.

The paper presents the results of examination of PM emissions from the Diesel engine FPT 1.3 MJT fuelled simultaneously with compressed natural gas (CNG) and diesel oil. The examination was performed for changing loads and rotational speeds, which reflected engine operation conditions. The recorded results can apply to both large railway Diesel engines, and marine engines installed on ships operating in offshore zones or used for passenger transport.

\section{TEST RIG}

The research was performed on a Diesel engine FPT 1.3 MJT. This is a four-cylinder engine with displacement of $1248 \mathrm{~cm}^{3}$. Direct fuel injection was executed by the second generation Common Rail type system with a so-called Multi Jet dose division system. The engine was adapted for double fuelling in the Department of Combustion Engines and Vehicles, University of Bielsko-Biala $[14,17,18]$. Technical data of the examined engine are given in Table 1

Tab. 1. Technical data of FPT 1.3 MJT[19]

\begin{tabular}{|l|l|}
\hline Engine type & $1.3 \mathrm{MJT}$ \\
\hline Bore x stroke & $69.6 \times 82 \mathrm{~mm}$ \\
\hline Displacement & $1248 \mathrm{~cm} 3$ \\
\hline Number of cylinders & 4 \\
\hline Cylinder arrangement & straight \\
\hline Compression ratio & 18 \\
\hline Maximum power & $51 \mathrm{~kW}$ at $4000 \mathrm{rpm}$ \\
\hline Maximum torque & $180 \mathrm{Nm}$ at $1750 \mathrm{rpm}$ \\
\hline Injection system & Common Rail \\
\hline Number of valves per cylinder & 4 \\
\hline Timing system & DOHC \\
\hline Exhaust gas recirculation system & EGR valve \\
\hline
\end{tabular}

In engine adaptation, use was made of the sequential gas injection set Oscar-N Diesel SAS produced by EuropeGAS $[14,17,20]$. This set can cooperate with an arbitrary type of Diesel engines, regardless the number of cylinders, their arrangement, air delivery system, or fuel injection system.

Engine adaptation for double fuelling required a new prototype inlet manifold, in which such elements as gas injectors, the gas rail, and gas tubes connecting gas injectors with inlet valve channels on particular cylinders were to be installed. The gas tubes had calibrated gas jets mounted on their ends. The prototype inlet manifold and the engine test rig are shown in Fig. 1.

a)

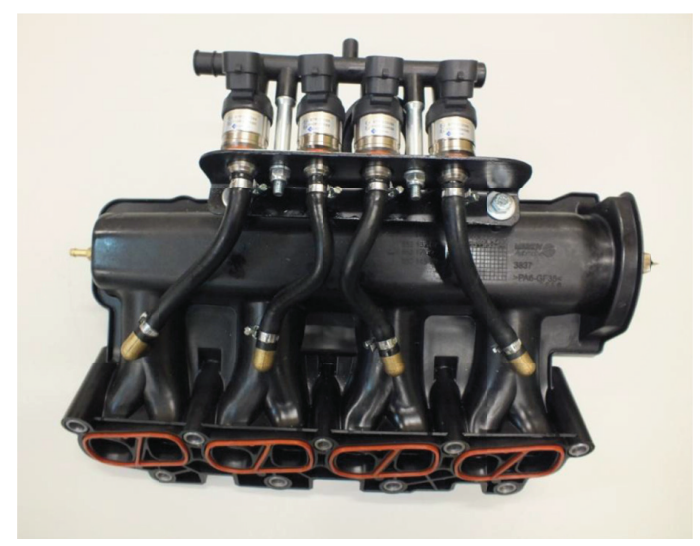

b)

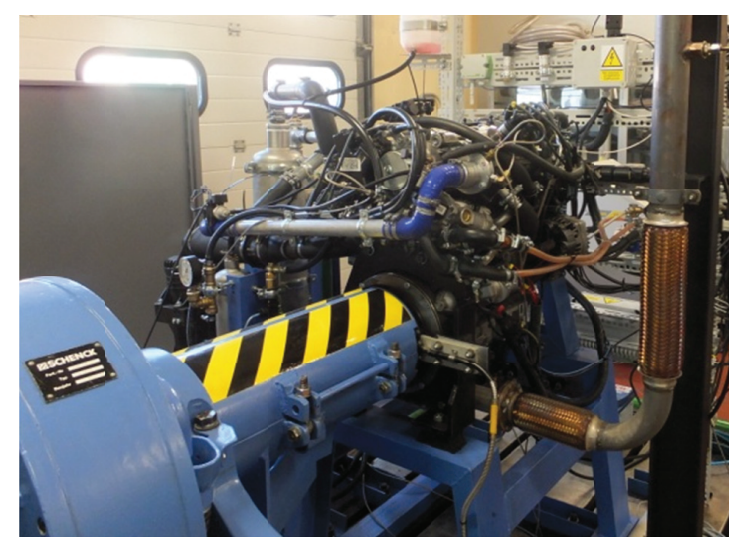

Fig. 1 Inlet manifold (a) and FPT 1.3 MJT engine test rig (b)

The operation of the dual fuel engine was controlled using the MJD 6JX type controller produced by Bosch. When accelerating, the controller automatically decreased the dose of diesel fuel to retain the required engine torque. In cases of large fuel dose changes, the air flow volume was also reduced.

\section{METHODOLOGY OF PM EMISSION EXAMINATION}

The performance assessment of contemporary Diesel engines takes into account, among other aspects, measurements of toxic exhaust gas components emitted in conditions corresponding to their road operation, i.e. at changing rotational speed, load 
and time. These measurements are performed on an engine test rig, according to New European Driving Cycle (NEDC) procedure. The here presented examination was performed at 20 static engine operation points in conditions $\left(n, M_{o}\right)=$ const mapping the NEDC test. The measuring points were selected using statistical analysis methods described in [11]. When selecting an individual measuring point $n-M_{0}$, the criterion of the longest engine operation mapping the NEDC test and the effect of measuring point selection on the results of total emission in the test were taken into account. The selected points represented both changing and constant driving speeds, Table 2. The points numbered 6, 7, 9, 12, 14, 15, 17 and 20 had the highest share in the NEDC test and corresponded to test phases with constant driving speed.

The exhaust gas opacity was measured using a precise filtration opacimeter, model 415 SE produced by AVL, with the FSN (Filter Smoke Number) scale or in $\mathrm{mg} / \mathrm{m}^{3}$.

The sizes of particles were measured using the spectrometer 3090 EEPS (Engine Exhaust Particle Sizer ${ }^{\mathrm{TM}}$ Spectrometer) produced by TSI Incorporated. This spectrometer provides opportunities for continuous analysis of dimensional distribution of the particles emitted by the engine. The diameter of the measured particulates ranged within $5,6 \div 560 \mathrm{~nm}$. The measurement was performed in 22 measuring channels at the measuring frequency of $10 \mathrm{~Hz}$.

Tab. 2. Selected engine operation measurement points [11]

\begin{tabular}{|c|c|c|c|}
\hline Item & $\begin{array}{l}\text { Rotational speed } \\
{[\mathrm{rpm}]}\end{array}$ & $\begin{array}{c}\text { Torque } \\
{[\mathrm{Nm}]}\end{array}$ & $\begin{array}{l}\text { Driving speed } \\
{[\mathrm{km} / \mathrm{h}] / \text { gear }}\end{array}$ \\
\hline 1 & 820 & 45 & \\
\hline 2 & 850 & 20 & \\
\hline 3 & 1050 & 15 & \\
\hline 4 & 1250 & 20 & \\
\hline 5 & 1400 & 40 & \\
\hline 6 & 1550 & 4 & $35 /$ III \\
\hline 7 & 1590 & 10 & $50 / \mathrm{IV}$ \\
\hline 8 & 1650 & 37 & \\
\hline 9 & 1730 & 11 & $70 / \mathrm{V}$ \\
\hline 10 & 1740 & 26 & \\
\hline 11 & 1800 & 38 & \\
\hline 12 & 1920 & 3 & $15 / \mathrm{I}$ \\
\hline 13 & 2050 & 26 & \\
\hline 14 & 2200 & 4 & 50/III \\
\hline 15 & 2260 & 4 & $32 / \mathrm{II}$ \\
\hline 16 & 2400 & 55 & \\
\hline 17 & 2500 & 34 & $100 / \mathrm{V}$ \\
\hline 18 & 2700 & 73 & \\
\hline 19 & 2930 & 80 & \\
\hline 20 & 3020 & 55 & $120 / \mathrm{V}$ \\
\hline
\end{tabular}

\section{ANALYSIS OF EXAMINATION RESULTS}

Gas injection to the inlet manifold not only increases the dose of energy delivered to the engine but also the volume of the medium sucked into it. When the factory controller is used and the load and rotational speed are kept constant, this means passing the controller to another operating point which corresponds to a smaller dose of the injected diesel oil and the sucked air, compared to fuelling with pure diesel oil. Therefore, to maintain identical operating conditions for traditional and dual fuelling, the amount of air is to be corrected with respect to that delivered by the controller, in such a way that the excess air number is kept approximately the same for both types of fuelling. A more detailed analysis of these issues is given in $[17,18]$.

Figure 2 shows real potential for reducing exhaust gas opacity by CNG addition, at constant opening time of gas injectors equal to $2,0 \mathrm{~ms}$, independently of engine operation conditions. The energy share of the injected gas at the examined measuring points changed within $24,6 \div 35,6 \%$. In fact, the exhaust gas opacity was decreased at all examined points. It is worth mentioning, however, that this effect required air flow rate correction in such a way that the excess air number was the same as that for traditional fuelling. This means in practice that in dual fuelling a special algorithm is to be used in the gas controller to control the excess air number, i.e. to play a function of the factory controller in traditional fuelling.

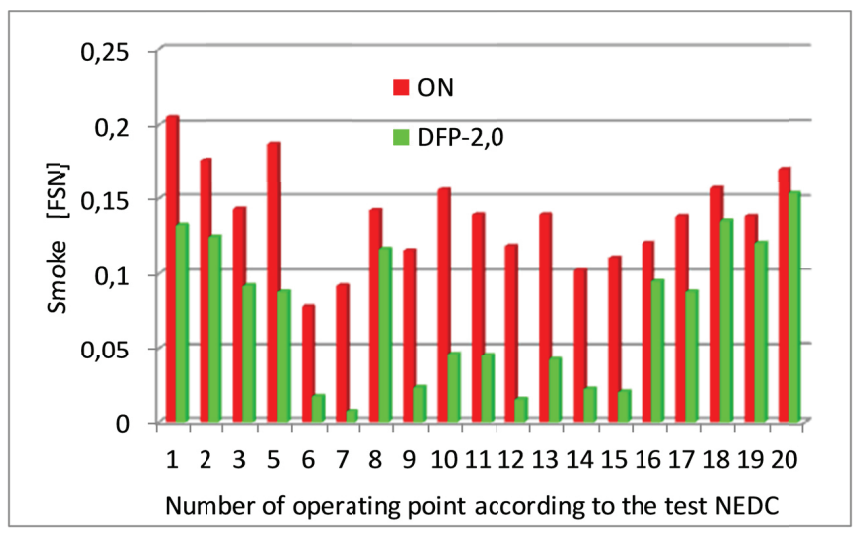

Fig. 2 Comparing exhaust gas opacity from traditionally and dual-fuelled engine with air flow rate correction: dual fuelling air flow rate the same as for diesel oil fuelling, gas injector opening time 2,0 ms

Relative change of the exhaust gas opacity with respect to that of diesel oil at a given measuring point can be calculated using the formula:

$$
\Delta D_{k D F-2,0}=100 \cdot \frac{D_{D F P-2,0}-D_{O N}}{D_{O N}}[\%]
$$

where:

$\Delta \mathrm{D}_{\mathrm{kDF}-2,0}$ is the relative exhaust gas opacity change at air flow rate correction and gas injector opening time of $2,0 \mathrm{~ms}$, $\mathrm{D}_{\text {DFP-2,0}}$ is the exhaust gas opacity of the dual fuel engine at gas injector opening time of $2,0 \mathrm{~ms}$, 
$\mathrm{D}_{\mathrm{ON}}$ is the exhaust gas opacity of the engine fuelled with diesel oil.

The data shown in Fig. 3 indicate that in the NEDC test driving conditions the relative exhaust gas opacity can be reduced at all measuring points, and this reduction can range within $10 \div 92 \%$. From the practical point of view concerning the particulate filter operation, of highest importance is the exhaust gas opacity reduction in increased engine load conditions, i.e. for operating points $1,2,5,8,10,11,13,16$, $17,18,19$ and 20 . The smoke opacity reduction at these points can reach $10 \div 80 \%$.

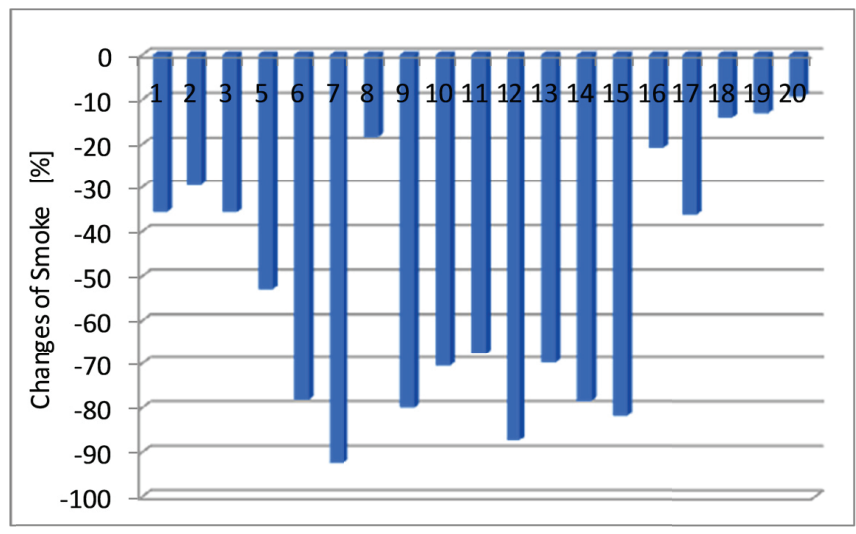

Fig. 3 Exhaust gas opacity changes for dual fuel engine working at points mapping the NEDC test (Table 2) with respect to pure diesel oil fuelling: air flow rate correction, gas injector opening time 2,0 ms, gas energy share $24,6 \div 35,6 \%$

Contemporary regulations concerning exhaust gas toxicity impose limits not only on the mass emission of particle matter (PM) expressed in $\left[\mathrm{mg} / \mathrm{m}^{3}\right]$, but also on the number of the emitted particles PN $[6,9]$. The latter requirement results from the fact that a larger number of emitted particles increases the share of small-diameter ones, which are, in epidemiologists' opinion, extremely dangerous for living organisms and remain in the atmosphere much longer than larger particles. That is why the particle measurements performed at points corresponding to the NEDC test also referred to the number of particles $\mathrm{PN}$ and their fractional distribution.

Figure 4 compares the total number of particles PN emitted by the engine fuelled with diesel oil with that recorded for the dual-fuelled engine at the gas injector opening times equal to $1,5 \mathrm{~ms}$ and $2,0 \mathrm{~ms}$, without air flow rate correction (all supply parameters were set by the factory controller, without outside interference). The analysis of Fig. 4 shows that at points characterised by small rotational speed and low load, the total number of emitted particles was smaller for dual fuelling than for traditional fuelling. Within the medium rotational speed and load range, the PN emission for the above two fuelling types were similar, while for larger rotational speeds and large load (points 14, 16, 18 and 19) the dual-fuel engine emitted larger numbers of particles, with simultaneous higher exhaust gas opacity. It is also noteworthy that further increase of the volume of the injected gas increased the emission of particles at those points.

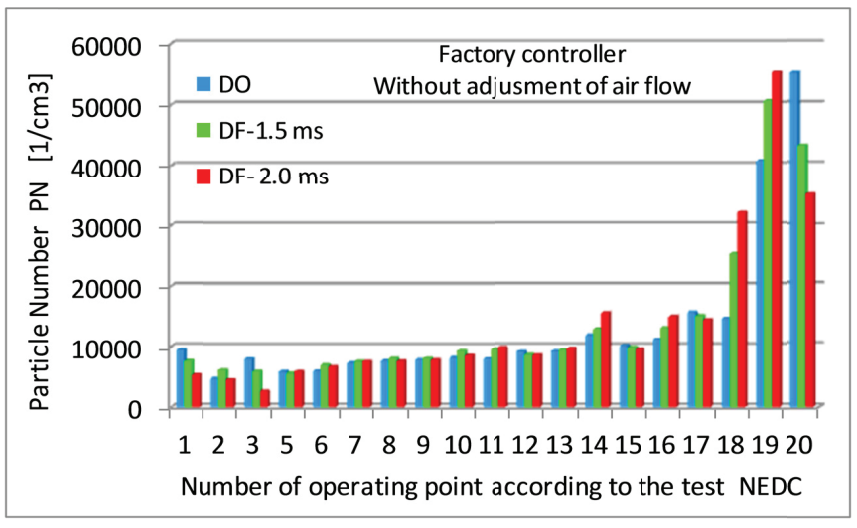

Fig. 4 Comparing total number of particles $P N$ in the exhaust gas from FPT 1.3 MJT engine, traditionally and dual-fuelled without air flow rate correction: factory controller, constant gas injector opening times 1,5 ms and $2,0 \mathrm{~ms}$

Correcting the air flow rate leads to the reduction of the number of particles emitted by the dual fuel engine, Fig.5. Almost at all analysed points the number of particles emitted by the dual fuel engine was smaller than that for traditional fuelling.

It is also noteworthy that at a large number of measuring points, differences in the number of emitted particles for gas injector opening times of 1,5 $\mathrm{ms}$ and 2,0 $\mathrm{ms}$ are small, and at some points the PN number for time 2,0 ms is larger than that for time 1,5 ms. Simultaneously, the exhaust gas opacity for time $2,0 \mathrm{~ms}$ is clearly smaller than that for time $1,5 \mathrm{~ms}$ at the examined points. Therefore, we can expect that at those points the increased gas share leads to the emission of a larger number of small particles.

Absolute differences in the number of particles $\triangle \mathrm{PN}$ between traditional and dual fuelling can be calculated from the formula:

$$
\Delta P N_{k D F-2,0}=P N_{k D F-2.0}-P N_{O N}
$$

where:

$\Delta \mathrm{PN}_{\mathrm{kDF}-2,0}$ is the difference between the number of particles emitted by the dual fuel engine with air flow rate correction and gas injector opening time equal to $2,0 \mathrm{~ms}$,

$\mathrm{PN}_{\mathrm{kDF}-2,0}$ is the number of particles emitted by the dual fuel engine,

$\mathrm{PN}_{\mathrm{ON}}$ is the number of particles emitted by the engine fuelled with diesel oil.

Figure 6 compares absolute differences $\Delta \mathrm{PN}_{\mathrm{kDF}-1,5}$ and $\Delta \mathrm{PN}_{\mathrm{kDF}-2,0}$ recorded at the measuring points. For the majority of points, these differences are smaller than $4000\left[1 / \mathrm{cm}^{3}\right]$. Large differences were only recorded at points 19 and 20 corresponding to rotational speeds of $2930 \mathrm{rpm}$ and 3020 rpm, and loads equal to o $80 \mathrm{Nm}$ and $55 \mathrm{Nm}$, respectively. These points refer to the driving speeds characteristic for 
the extra-urban test phase. The reduction in the number of emitted particles equalled $15.000 \div 24.000\left[1 / \mathrm{cm}^{3}\right]$ at point 19 and $26.500 \div 32.000\left[1 / \mathrm{cm}^{3}\right]$ at point 20 .

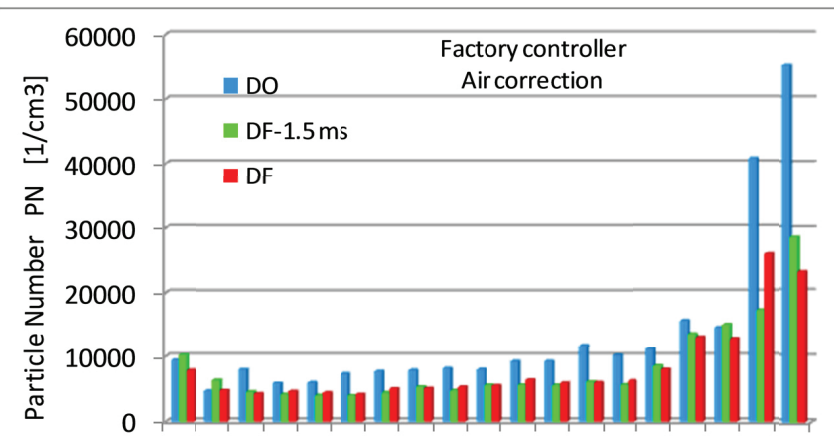

$\begin{array}{llllllllll}1 & 2 & 3 & 5 & 6 & 7 & 8 & 9 & 1011 & 121314151617181920\end{array}$ Number of operating point according to the test NEDC

Fig. 5 Comparing total number of particles PN in the exhaust gas from FPT 1.3 MJT engine, traditionally and dual-fuelled with air flow rate correction: factory controller, constant gas injector opening times $1,5 \mathrm{~ms}$ and 2,0

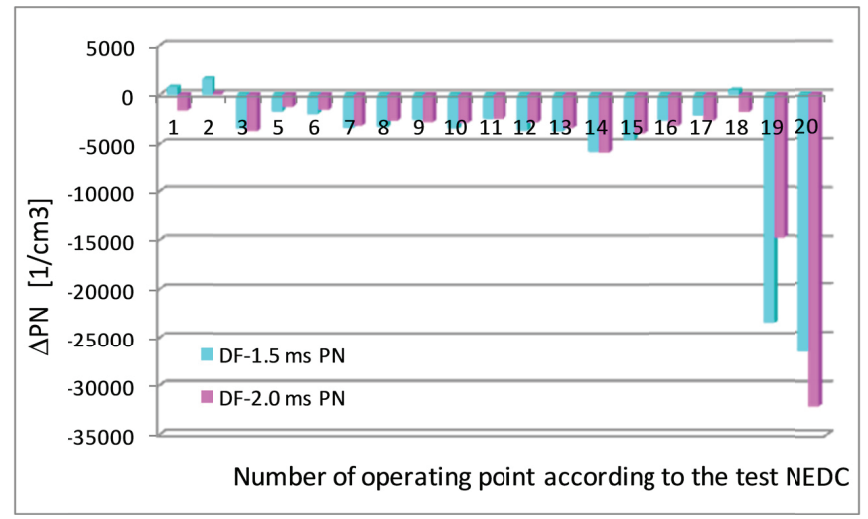

Fig. 6 Comparing absolute differences in the number of particles emitted by dual fuel engine at different gas injector opening times - 1,5 ms and 2,0 ms

Relative differences in the number of particles PN between traditional and dual fuelling can be calculated from the formula:

$$
\delta P N_{k D F-2,0}=100 \cdot \frac{P N_{k D F-2,0}-P N_{O N}}{P N_{O N}}[\%]
$$

where:

$\delta \mathrm{PN}_{\mathrm{kDF}-2,0}$ is the relative difference between the number of particles emitted by the dual fuel engine with air flow rate correction and gas injector opening time $2,0 \mathrm{~ms}$,

$\mathrm{PN}_{\mathrm{kDF}-2,0}$ is the number of particles emitted by the dual fuel engine,

$\mathrm{PN}_{\mathrm{ON}}$ is the number of particles emitted by the engine fuelled with diesel oil.

The analysis of relative differences shown in Fig. 7 indicates that in dual fuel engines the total number of particles emitted in the NEDC test can be reduced approximately by $30 \div 40 \%$, which should be considered a very large value from the point of view of environment protection. Of high importance is also the fact that the $\mathrm{PN}$ reduction was observed at almost all measuring points, also for small rotational speeds and engine loads, which corresponds to urban driving conditions.

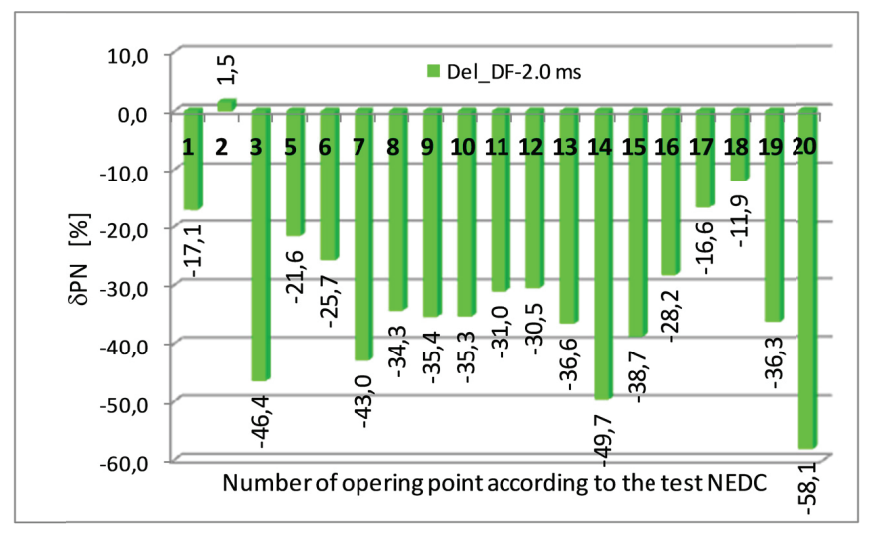

Fig. 7 The effect of air flow rate correction on the total number of particles PN in the exhaust gas from traditionally and dual-fuelled FPT 1.3 MJT engine: factory controller, gas injector opening time 2,0 ms

Fractional distributions of the emitted particles are compared at four points selected from the total number of 20 measuring points examined in the NEDC test. Two points correspond to engine operation conditions in which gas addition resulted in the decrease of the number of emitted particles (Figs. 8 and 11), while at two remaining points the increase of PN emission was observed (Figs 9 and 10). The comparison shows that a basic portion of the emitted particles has the diameters ranging between $16,5 \div 339,8 \mathrm{~nm}$. At the rotational speed of $900 \mathrm{rpm}$ and load $45 \mathrm{Nm}$, the majority of particles have dimensions of $25.5 \div 93,1 \mathrm{~nm}$, Fig. 8. Gas addition corresponding to the gas injector opening time of 2,0 $\mathrm{ms}$ decreases the emission of particles with dimensions corresponding to largest emissions, while within the smallest and large diameter ranges the PM emissions for diesel oil and dual fuelling are similar.

At point 18, corresponding to the rotational speed 2700 rpm and load $73 \mathrm{Nm}$ (Fig. 9), the fractional distributions for traditional and dual fuelling are similar. The increased emission at dual fuelling is observed within a wide range of particle dimensions, $19,1 \div 165,5 \mathrm{~nm}$. Characteristically, the share of large particles, of $191,1 \div 339,8 \mathrm{~nm}$, is negligibly small. Shifting the dimensional range of the emitted particles towards smaller diameters at higher rotational speeds can be related to the increase of the medium temperature, but also to a shorter response time, which does not allow for coagulation of larger particles. 


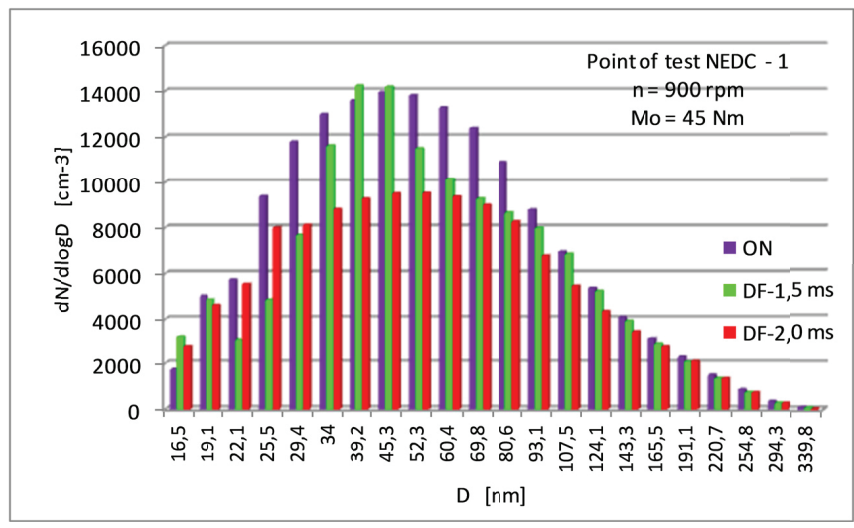

Fig. 8 Comparing fractional distributions of particles, $d N / d \log D$, for traditionally and dual-fuelled FPT 1.3 MJT engine: point 1 acc. to NEDC test, $n=900 \mathrm{rpm}, M o=45 \mathrm{Nm}$, gas injector opening times $1,5 \mathrm{~ms}$ and 2,0 $\mathrm{ms}$

Further rotational speed increase shifts the particle creation process towards smaller particle dimensions. For point 19, characterised by rotational speed of $2930 \mathrm{rpm}$ and load of $80 \mathrm{Nm}$, the largest numbers of the emitted particles have dimensions within $22,1 \div 69,8 \mathrm{~nm}$, Fig. 10. Also within this range, the numbers of particles emitted at dual fuelling are larger than at diesel oil fuelling. Without charging air correction, the increase of the injected gas is accompanied by the increase in the number of emitted particles, with larger differences taking place within the small-dimension range.

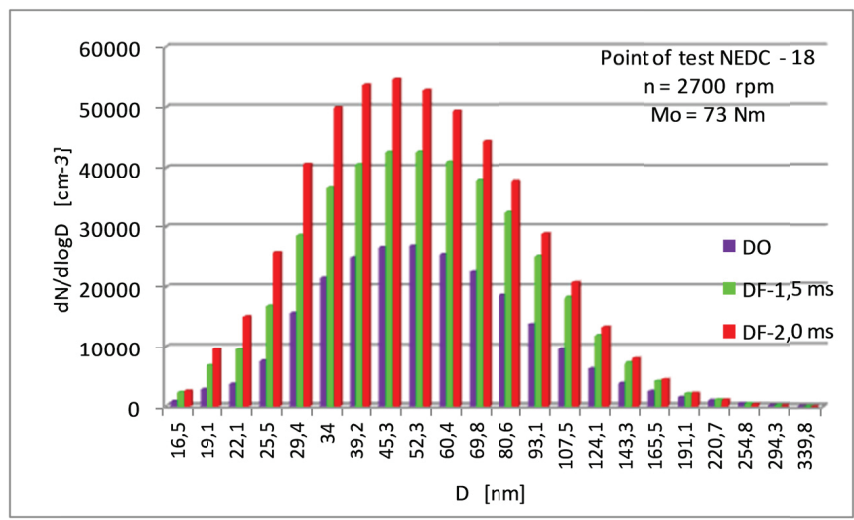

Fig. 9 Comparing fractional distributions of particles, $d N /$ dlogD, for traditionally and dual-fuelled FPT 1.3 MJT engine: point 18 acc. to NEDC test, $n=2700 \mathrm{rpm}, \mathrm{Mo}=73 \mathrm{Nm}$, gas injector opening times $1,5 \mathrm{~ms}$ and 2,0 ms

At point 20, characterised by rotational speed of 3020 rpm and load of $55 \mathrm{Nm}$, Fig. 11, the larger number of the created particles have dimensions within $19,1 \div 69,8 \mathrm{~nm}$. At dual fuelling, the ranges of largest numbers of particles are shifted towards larger particle dimensions. Since the particles are created as a result of thermal cracking of diesel oil, the creation of larger particles can testify to worsened quality of liquid fuel combustion, due to lower oxygen concentration and simultaneous higher concentration of carbon dioxide. Decreasing the combustion rate prolongs the fuel oxidation process, which fosters particle coagulation into larger aggregates. Simultaneously, lower oxygen concentration in the charge leads to the decrease of the excess air number in liquid fuel combustion zones, providing good opportunities for the creation of a large number of primary particles. The decrease in the total number of particles at dual fuelling, which can be observed in the fractional distribution in Fig. 11 , can be interpreted as the result of smaller amount of diesel oil delivered in one working cycle, with simultaneous burning up of primary soot particles in the combusting mixture. The combusting gas/air mixture decreases the rate of cooling of liquid fuel combustion products which fosters the soot particle burning up process.

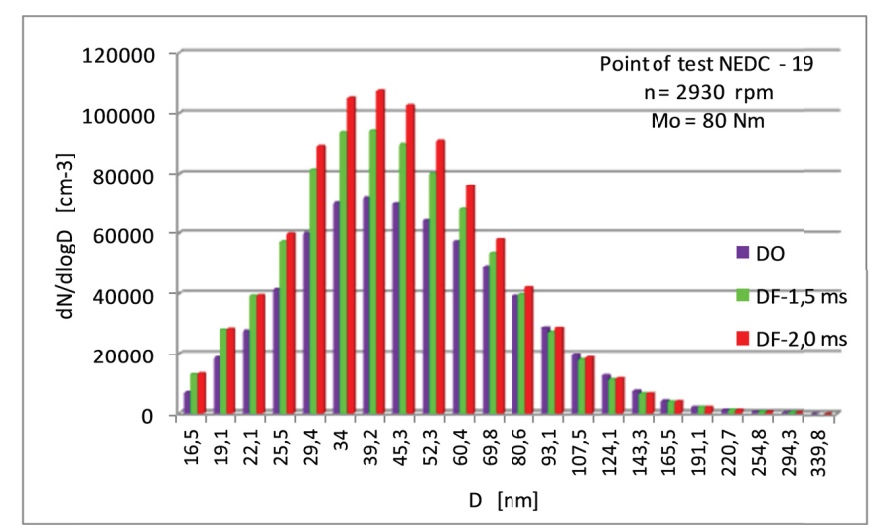

Fig. 10 Comparing fractional distributions of particles, $d N /$ dlogD, for traditionally and dual-fuelled FPT 1.3 MJT engine: point 19 acc. to NEDC test, $n=2930 \mathrm{rpm}, M o=80 \mathrm{Nm}$, gas injector opening times $1,5 \mathrm{~ms}$ and 2,0 ms

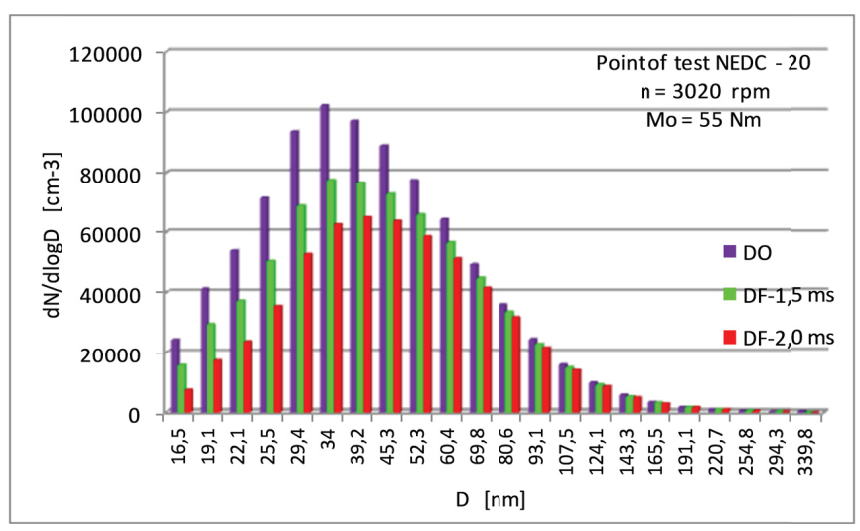

Fig. 11 Comparing fractional distributions of particles, $d N /$ dlogD, for traditionally and dual-fuelled FPT 1.3 MJT engine: point 20 acc. to NEDC test, $n=3020 \mathrm{rpm}, M o=55 \mathrm{Nm}$, gas injector opening times 1,5 ms and 2,0 ms

Within the range of particle dimension larger than $69,8 \mathrm{~nm}$, the numbers of the particles created at gas addition are similar to those recorded for pure diesel oil fuelling. The amount of the added gas within this range does not affect the number of the created particles.

Figures $12 \div 13$ compare fractional distributions of the numbers of created particles at diesel oil fuelling and at dual fuelling with air flow rate correction. As a result of this correction, the supercharging pressure in the dual fuel engine became comparable with that for traditional fuelling. The air flow rate correction decreased the numbers of created particles 
at all examined measuring points, and these numbers were considerably smaller than the corresponding values recorded in the traditionally fuelled engine.

It is noteworthy here that precise air flow rate correction, measured in [mg/cycle] would require taking into account the volume of the gas in the sucked charge, which would lead to slight increase of the supercharging pressure for the specific air flow rate be the same for both fuelling systems. However, such precise correction was not possible, as the engine operation controller switched to "emergency" mode in those cases. Achieving such precise correction in the examined engine would require global reprogramming of the factory controller, which was not possible.

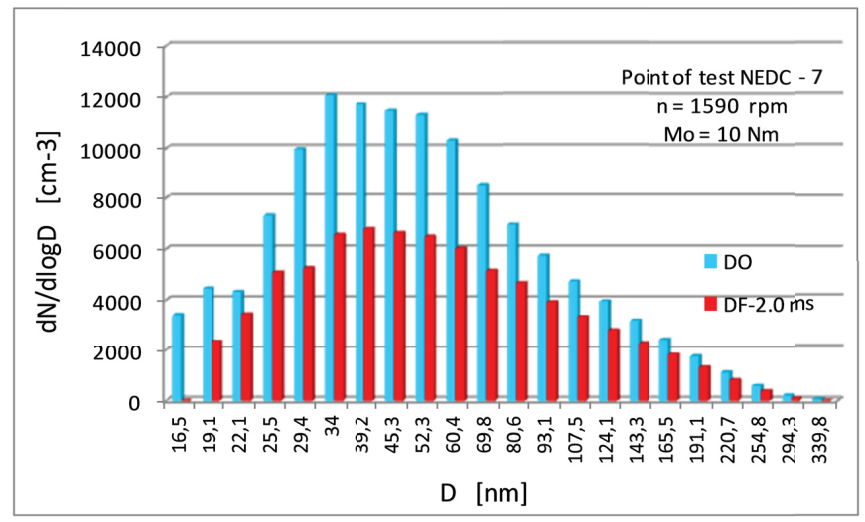

Fig. 12 Comparing fractional distributions of particles, $d N /$ dlogD, for traditionally and dual-fuelled FPT 1.3 MJT engine: point 7 acc. to NEDC test, $n=1590 \mathrm{rpm}, M o=10 \mathrm{Nm}$, gas injector opening time 2,0 $\mathrm{ms}$

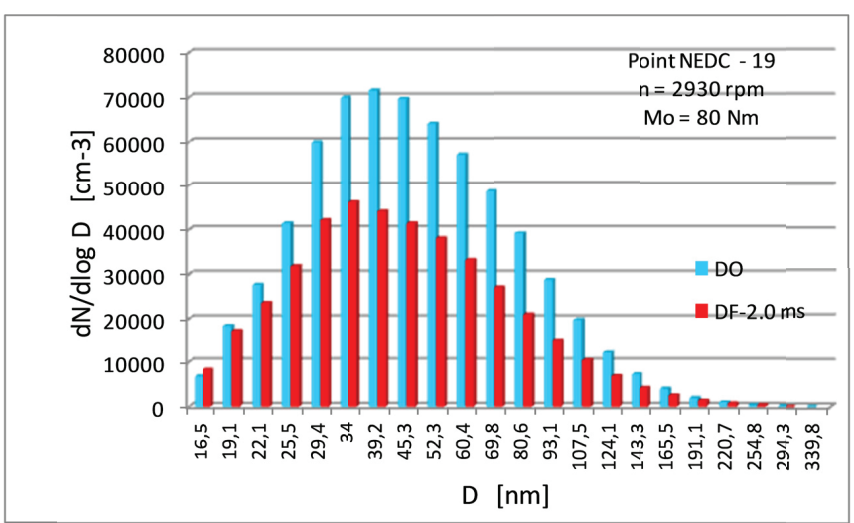

Fig. 13 Comparing fractional distributions of particles, $d N /$ dlogD, for traditionally and dual-fuelled FPT 1.3 MultiJet engine: point 19 acc. to NEDC test, $n=2930 \mathrm{rpm}, \mathrm{Mo}=80 \mathrm{Nm}$, gas injector opening time 2,0 ms

\section{CONCLUSIONS}

Dual fuelling of modern Diesel engines can contribute to the reduction of particulate matter emission, especially in urban traffic conditions. It should result in prolonging the time between successive regenerations of DPF filters and their total lifetime, and in increasing the engine reliability.
The addition of the natural gas, CNG, to the diesel oil reduces the smoke opacity and PM emission in the exhaust gas. In modern Diesel engines equipped with high-pressure injection systems of Common Rail type and electronic engine operation control, special controllers are to be used in dual fuelling systems to control the quality of the charge. These controllers should make use of different controlling procedures than those traditionally used in factory controllers. This mainly refers to air flow rate correction at decreasing share of liquid fuel, but also to the method of liquid fuel dose division and injection times for partial doses [18].

The performed research has shown that air flow rate correction provides opportunities for decreasing exhaust gas opacity (Filter Smoke Number - FSN) and total number PN of emitted particles. This effect was observed at all twenty engine operation points selected as corresponding to the NEDC test, which is promising for potential positive driving tests during car inspections. The exhaust gas opacity reduction amounted to $10 \div 92 \%$, and the reduction of the total number of particles, PN, by $30 \div 40 \%$, depending on engine operation conditions. Of high importance is the reduction of PM emission at higher rotational speeds and engine loads, when this emission is more intensive. This is also promising for DPF filter operation in extra-urban driving tests, which should positively affect its lifetime.

The above effects cannot be achieved using factory controllers with overlapping dual fuel installations. The tests have proved that at points at which the factory controller decreases the air flow rate the use of additional gas dose can increase the exhaust gas opacity an PM emission.

The fractional analysis has shown that the basic portion of the created particles has dimensions within $16,5 \div 339,8 \mathrm{~nm}$. The increase of rotational speed and engine load increases the number of particles with smaller diameters, for instance for the speed of $2930 \mathrm{rpm}$ and load of $80 \mathrm{Nm}$ the highest number of particles had diameters within $22,1 \div 69,8 \mathrm{~nm}$. This most likely resulted from higher medium temperatures during combustion which facilitated burning up of particles, but also from shorter combustion time which did not allow for coagulation of larger soot particles.

Within the range of smaller rotational speeds and low engine loads, the fractional distribution of the particles emitted at dual fuelling was similar to that observed in traditional fuelling. At higher engine loads and dual fuelling, the basic portion of particles had larger diameters than those created during traditional fuelling, which can testify to worsened conditions for oxidation of partial liquid fuel doses injected during active combustion in the conditions of lower oxygen concentration and the presence of carbon dioxide in the exhaust gas. This fact should be taken into account in algorithms dividing the liquid fuel dose for dual fuelling. These issues need further research.

In engines equipped with DPF filter, the action of this filter can make the effect of gas addition much smaller in test conditions. It is expected, however, that during engine operation, the positive effect of gas addition on the PM emission will significantly decrease the load of the DPF filter, 
thus contributing to the decrease of the emission of toxic components during filter regeneration.

The research was performed within the framework of the research project No. PBS1/A6/13/2012 entitled: "Reducing smoke opacity and particulate matter emission in the exhaust gas from car Diesel engines via CNG addition". The project was financed by the National Centre for Research and Development.

\section{BIBLIOGRAPHY}

1. Barroso P., Ribas X., Domingues J., De Sella E., Garcia J M., Study of dual-fuel (diesel+natural gas) particle mater and $\mathrm{CO} 2$ emissions of a heavy-duty diesel engine during transient operations, Combustion Engines, No. 2/2013 (153) ISSN 0138-0346, pp. 28-39.

2. Clark N N., Atkinson Chr M., Atkinson R J., McDaniel T., Park T., Optimized Emission Reduction Strategies for Dual Fuel Compression Ignition Engines Running on natural Gas and Diesel, http//www.cemr.wvu.edu 2002, pp.1-6.

3. Daisho Y., Takahashi K., Controlling combustion and exhaust emissions in a direct-injection diesel engine dual fuelled with natural gas, SAE Paper no 952436, 1995.

4. Ehsan Md., Bhuijan Sh., Dual Fuel performance of a Small Diesel Engine for Applications with Less Frequent Load Variations, International Journal of Mechanical \& Mechatronics Engineering IJMME Vol. 9 No. 10, 2011.

5. Gebert K., Beck J, Barkhimer R L., Wong H Ch., Strategies to Improve Combustion and Emission Characteristics of Dual-Fuel Pilot Ignited Natural Gas Engines, SAE Paper 1997, No 971712, pp. 79-87.

6. Kozak M., A study of the effect of oxygenates in diesel oil on the emission of toxic exhaust gas components from Diesel engines (in Polish), D.Sc. Monograph, Wydawnictwo Politechniki Poznańskiej, Poznań 2013.

7. Matyjasik M., Activation of the gas-air mixture combustion process in dual fuel engines via division of the initiating dose of diesel oil (in Polish), Ph.D. thesis, Bielsko-Biała 2012.

8. Merkisz J., Daszkiewicz P., Idzior M., Bajerlein M., Fuć P., Lijewski P., Analysis of reducing the emission of toxic exhaust gas components in dual fuel Diesel engine (in Polish), Logistyka, No. 6/2014, pp. 7260-7269.

9. Merkisz J., Pielecha J., Particulate matter emission from motorisation sources (in Polish), Wydawnictwo Politechniki Poznańskiej, Poznań 2014, 309 p., ISBN,978-83-7775-325-5.

10. Merkisz J., Pielecha J., Labędź K., Stojecki A., Examining the exhaust gas emission from different emission class vehicles fuelled with natural gas (in Polish), Prace Naukowe Politechniki Warszawskiej, Transport. 2013, pp. 463-472, ISSN,1230-9265.

11. Pietras D., Sobieszczański M., Świątek A., Pajdowski P., Selecting 1.3 multi-jet engine operation parameters characteristic for the NEDC test for development research purposes (in Polish), Silniki Spalinowe, No. PTNSS P05-C065.

12. Stelmasiak Z., A study of gas combustion process in dual fuel Diesel engine fuelled with natural gas and diesel oil (in Polish), Wydawnictwo ATH, D.Sc. dissertation, BielskoBiała 2003.

13. Stelmasiak Z., Dual fuel Diesel engines (in Polish), Wydawnictwo Naukowe Instytutu Technologii Eksploatacji, Biblioteka Problemów Eksploatacji, Radom 2013.

14. Stelmasiak Z., Larisch J., Dual fuelling of Fiat 1.3 MultiJet engine (in Polish). Logistyka 6/2014.

15. Stelmasiak Z., Larisch J., Pietras D., The effect of natural gas addition on smoke opacity of the exhaust gas from a car Diesel engine (in Polish), Combustion Engines No. 3/2015.

16. Stelmasiak Z., Larisch J., Pietras D., The effect of natural gas addition on selected operating parameters of double fuelled Fiat 1.3 MultiJet engine (in Polish), Combustion Engines No. 3/2015.

17. Stelmasiak Z., Larisch J, Pietras D., Selected problems of adaptation car diesel engine for dual fuel supplying, Combustion Engines no. 3/2015 (162), p. 1021-1029.

18. Stelmasiak Z. Larisch J. Pietras D., Some problems of controlling the car diesel engine powered dual fuel, Combustion Engines no. 3/2015 (162) pp. 1070-1081.

19. Materials of FIAT AUTO POLAND, 2014.

20. Technical materials of EuropeGAS, 2013.

21. Reduction of SO2, NOx and Particulate Matter from Ships with Diesel Engines. Environmental Project no. 1510, 2014.

22. Pyć D., Remarks by De Lege Ferenda to the status of the Baltic Sea as the area of control of nitrogen oxide emission from sea-going vessels (in Polish). Maritime Law, vol. XXVIII, ISSN 0860-7338, pp. 235-247.

23. ht t p s:// w w w. e pa.gov/regulations e mi s s i o n s-vehicles-and-engines/ domestic-regulations-emissions-marine-compression

24. Fuc P., Rymaniak L., Ziolkowski A., The correlation of distribution of PM number emitted under actual conditions 
of operation by PC and HDV vehicles. AIR POLLUTION XXI Book Series: WIT Transactions on Ecology and the Environment Volume: 174 Pages: 207-218 Published: 2013, ISSN: 1743-3541, DOI: 10.2495/AIR130181

\section{CONTACT WITH THE AUTHOR}

Zdzisław Stelamasiak

e-mail: zstelmasiak@ath.bielsko.pl

Jerzy Larisch

e-mail: jlarisch@ath.biesko.pl

Dariusz Pietras

e-mail:pietras@ath.bielsko.pl

University of Bielsko-Biała

Willowa 2

43-309 Bielsko-Biała

Jacek Pielecha

e-mail: jacek.pielecha@put.poznan.pl

Poznań University of Technology

Piotrowo 3

60-965 Poznan

Poland 